\title{
Bioaccumulation and biosorption of inorganic nanoparticles: factors affecting the efficiency of nanoparticle mycoextraction by liquid-grown mycelia of Pleurotus eryngii and Trametes versicolor
}

\author{
M. Jakubiak • I. Giska • M. Asztemborska • \\ G. Bystrzejewska-Piotrowska
}

Received: 1 July 2013 /Revised: 16 September 2013 /Accepted: 22 September 2013 / Published online: 11 October 2013

(C) The Author(s) 2013. This article is published with open access at Springerlink.com

\begin{abstract}
Nanoparticles (NPs) could reach the food chain from diverse wastes containing these potentially toxic substances. We studied the mycoextraction of alumina $\left(\mathrm{Al}_{2} \mathrm{O}_{3}\right)$ NPs by mycelia of edible fungi: Pleurotus eryngii and Trametes versicolor. Mycelia were cultivated in liquid medium supplemented with alumina nanoparticles (concentrations $0.001-$ $0.1 \mathrm{~mol} \mathrm{~L}^{-1}$ ) to investigate accumulation of metal in the mycelium. The accumulation of $\mathrm{Al}$ in the mycelium depended on the duration of exposure, biomass of the mycelium and concentration of NPs. The efficiency of alumina-NP removal from the medium depended only on the duration of exposure and the fungal biomass, but not on NP concentration. Live hyphae of $P$. eryngii were more efficient in the removal of the NPs ( $\sim 86 \%$ of total amount of NPs removed from medium) than T. versicolor (61\%). Dead mycelium of P. eryngii was less efficient (51\%), but also useful in the mycoextraction. These results were confirmed by scanning and transmission electron microscopy and laser ablation inductively coupled plasma mass spectrometry. Additionally, it was found that the mycoextraction efficiency by P. eryngii depended on NP type and was lower for NPs other than alumina: platinum $-58 \%$ and cobalt $-13 \%$.
\end{abstract}

Keywords Alumina nanoparticles · Platinum nanoparticles · Cobalt nanoparticles $\cdot$ Bioaccumulation · Biosorption · Mycoextraction · Bioremediation · Pleurotus eryngii . Trametes versicolor

M. Jakubiak $\cdot$ I. Giska $\cdot$ M. Asztemborska G. Bystrzejewska-Piotrowska $(\bowtie)$

Isotope Laboratory, Faculty of Biology, University of Warsaw, Miecznikowa 1, 02-096 Warsaw, Poland

e-mail: byst@biol.uw.edu.pl

\section{Introduction}

Mycoextraction is a process in which fungi are used for the removal of contaminants from soil or water. The main mechanisms of accumulation of toxic substances by organisms are biosorption and bioaccumulation. Biosorption is a metabolically passive process, in which pollutants are bound to the surface of cell wall. Bioaccumulation is a metabolically active process, based on incorporation of compounds or ions inside living biomass (Chojnacka 2010; Velásquez and Dussan 2009).

A high accumulation level is crucial for efficient bioextraction of pollutants from the environment and its bioremediation. Bioremediation is the application of biological systems to the cleanup of organic and inorganic pollution, with bacteria and fungi being the most important organisms for reclamation, immobilization or detoxification of metallic and radioactive pollutants (Gadd 2010). Certain fungi, in particular "white fungi”, can inactivate insecticides, herbicides, heavy fuels, and diverse toxic elements (Pointing 2001; Christian et al. 2005). It was documented that macrofungi are effective accumulators of silver (Borovicka et al. 2010). Among others, fungi have been shown to biomineralize uranium oxides, suggesting that they may have application in the bioremediation of radioactively polluted sites (Fomina et al. 2007, 2008). One of such fungi is Pleurotus eryngii, analyzed in our laboratory, which accumulates cesium in the fruitbody (Bystrzejewska-Piotrowska et al. 2008; Bazała et al. 2005, 2008) and in biotechnologically cultivated mycelium. The ubiquity and importance of fungi in environmental processes make mycoextraction one of the most promising strategies of bioremediation. On the other hand, the ability of fungi to accumulate toxins to high concentration makes them potentially dangerous for consumers. 
Recently, new potentially toxic products in the form of manufactured nanoparticles have appeared on the market. Nanotechnology is one of the most rapidly developing areas of technology, dealing with nanoparticles (NPs) - particles in which at least one of the dimensions does not exceed $100 \mathrm{~nm}$. Such particles exhibit novel physical, chemical and biological properties, different from their larger counterparts and resulting from their high ratio of surface area to volume or mass (Aitken et al. 2004). NPs are more reactive than conventional micron-sized particles (Rai et al. 2006). Owing to rapidly developing nanotechnologies, the worldwide market for nanomaterials is estimated to reach 100 billion dollars per annum for 2011-2014 (Podila and Brown 2013), and the potential impact of these new materials on the environment requires careful consideration. The increasing implementation of nanotechnologies brings with it the risk of creating a new generation of waste (nanowaste) and new potential threats to the environment (as reviewed by Bystrzejewska-Piotrowska et al. 2009). Production, use, and waste-disposal of NPs may lead to their release into the environment, so there is a growing need for the investigation of the accumulation and toxicity of NPs and means of their efficient removal or deactivation.

Aluminum oxide $\left(\mathrm{Al}_{2} \mathrm{O}_{3}\right)$ nanoparticles (alumina NPs) are among the most important nanomaterials and are widely used in diverse areas. Alumina is estimated to account for approximately $20 \%$ of the 2005 world market of nanoparticles (Rittner 2002). Alumina was listed as a high-priority group by the Organization for Economic Cooperation and Development (OECD) Steering Group for Test Guidelines (Park et al. 2010). Alumina NPs are widely used in catalysts, fine ceramics, paint, waterproofing, polishing, and fluorescent materials, and as a cosmetic UV filter; therefore, they can be found in many commercial products (Stenger et al. 2005; Huang et al. 2007; Schmid and Riediker 2008). Consequently, an increasing accumulation of $\mathrm{Al}_{2} \mathrm{O}_{3} \mathrm{NPs}$ in the environment can be expected.

Few studies have been conducted to investigate the toxicity of $\mathrm{Al}_{2} \mathrm{O}_{3}$-NPs. Aluminum is relatively stable in the form of alumina (aluminum oxide) and can enter the body through drinking water, food intake, inhalation and skin contact (Yang et al. 2012). Manufactured alumina NPs have been found to decrease the expression of tight junction proteins in brain vasculature (Chen et al. 2008). The effect of alumina nanoparticles (the growth inhibition and decrease in chlorophyll content) on microalgae Scenedesmus sp. and Chlorella sp. was demonstrated (Sadiq et al. 2011). Additionally, the temporal changes in physico-chemical behavior of $\mathrm{Al}_{2} \mathrm{O}_{3} \mathrm{NPs}$ in the environment were found (Pakrashi et al. 2012).

Efficient removal of NPs from a contaminated environment should prevent their ecotoxicity (as reviewed by Oberdorster et al. 2005). There is a lack of information about the accumulation of $\mathrm{Al}_{2} \mathrm{O}_{3}$-NPs in fungi. Recently, Bakircioglu et al. (2010) demonstrated that filamentous fungal biomass-loaded $\mathrm{TiO}_{2}$ NPs could be used for the biosorption of lead (II) ions.
Based on their results, establishing conditions for optimal recovery of nNPs from the environment seems worthwhile.

The aim of this study was the examination of:

i. applicability of biotechnological method of culturing of Pleurotus eryngii and Trametes versicolor mycelium;

ii. factors affecting the efficiency of $\mathrm{Al}_{2} \mathrm{O}_{3} \mathrm{NP}$ mycoextraction by live and dead fungal biomass;

iii. comparison of mycoextraction efficiency of alumina and other NPs (platinum $[\mathrm{Pt}]$, cobalt $[\mathrm{Co}]$ ).

\section{Materials and methods}

\section{Cultivation of Pleurotus eryngii and Trametes versicolor}

The king oyster mushroom P. eryngii (DC.) Quel 1872 was isolated from a fruitbody growing on the roots of Eryngium campestre L., a plant found in the locality of Camarma de Esteruelas $\left(3^{\circ} 22^{\prime} 45^{\prime \prime} \mathrm{W}, 40^{\circ} 33^{\prime} 15^{\prime \prime} \mathrm{N}, 30 \mathrm{~T} 4684489\right.$ UTM; Madrid Province, Spain) (Bystrzejewska-Piotrowska et al. 2008). The mushroom T. versicolor (L.) Lloyd 1920 (cat. no. CCBAS612) was obtained from the Institute of Microbiology, Academy of Sciences of the Czech Republic. Procedures for cultivation of Pleurotus eryngii under laboratory conditions have been described (Manjon et al. 2004; Bystrzejewska-Piotrowska et al. 2008; Bazała et al. 2008; Bystrzejewska-Piotrowska and Bazała 2008), but are limited to fungi with fruitbodies growing on solid medium, usually barley seeds. In this work, a method of cultivation of mycelia of $P$. eryngii and $T$. versicolor in liquid growth medium is proposed. For this purpose, PDY medium consisting of $4 \mathrm{~g} \mathrm{~L}^{-1}$ potato extract (Fluka, Poznan, Poland), $20 \mathrm{~g} \mathrm{~L}^{-1}$ dextrose (Sigma, Poznan, Poland) and $2 \mathrm{~g} \mathrm{~L}^{-1}$ yeast extract (Fluka, Poznan, Poland) was used. To the PDY medium, NPs of $\mathrm{Al}_{2} \mathrm{O}_{3}\left(\mathrm{Al}_{2} \mathrm{O}_{3} \mathrm{NPs}\right.$ particle size $<50 \mathrm{~nm}$, Sigma-Aldrich) were added, to obtain concentrations of $0.001,0.01,0.05$ or $0.1 \mathrm{~mol} \mathrm{~L}^{-1}$. In each experiment, control cultivation without NPs was performed. All growth media were autoclaved at $121{ }^{\circ} \mathrm{C}$ for $15 \mathrm{~min}$ and inoculated with three pieces of mycelium under sterile conditions. Each variant of the experiment was performed in at least three replicates. Mycelium was grown for 2 or 7 days on an orbital shaker $(120 \mathrm{rpm})$ at $25^{\circ} \mathrm{C}$. The same method was applied for cultivation of $P$. eryngii on medium contaminated with nanoparticles of $\mathrm{Pt}$ and $\mathrm{Co}$ (Pt-NPs, particle size $<50 \mathrm{~nm}$, Co-NPs, particle size $<50 \mathrm{~nm}$, both from SigmaAldrich).

After finishing the cultivation, the mycelium was separated from the medium by filtration through a double layer of sterile gauze.

For investigation of alumina-NPs accumulation by dead mycelium, control mycelium of $P$. eryngii was frozen at $-22{ }^{\circ} \mathrm{C}$, lyophilized and again introduced into NP-contaminated growth 
medium. After 7 days, mycelium was separated from the medium as above.

For total analysis of the metal content, mycelia samples were dried at $60{ }^{\circ} \mathrm{C}$ for $48 \mathrm{~h}$, weighed and homogenized in a mortar.

\section{Analysis of metal content}

For determination of $\mathrm{Al}, \mathrm{Pt}$ and $\mathrm{Co}$ content in the mycelia, about $250 \mathrm{mg}$ of dried material was digested with a mixture of $2.5 \mathrm{~mL} \mathrm{HNO}_{3}$ and $0.5 \mathrm{~mL} \mathrm{HClO}_{4}$ using a microwave laboratory system ETHOS 1 with ATC-400-CE automatic temperature control (Milestone, Italy). After digestion samples were quantitatively transferred into volumetric flasks $(25 \mathrm{~mL})$ and analyzed by inductively coupled plasma mass spectrometry ICP MS (ELAN 6000 ICP mass spectrometer, PE-SCIEX, Concord, Canada). Accumulation efficiency was calculated according to the equation:

total metal accumulated in mycelium $[\mathrm{mg}] /$ metal content in solution $[\mathrm{mg}] \times 100 \%$
A thin slice of a fresh P. eryngii mycelium sphere $\left(\mathrm{Al}_{2} \mathrm{O}_{3}\right.$ NPs concentration $0.1 \mathrm{~mol} \mathrm{~L}^{-1}$ ) was cut and $\mathrm{Al}$ was determined in the cross section of the mycelium using laser ablation inductively coupled plasma mass spectrometry (LA ICP MS, ELAN 6000 ICP mass spectrometer).

\section{Electron microscopy analysis}

Mycelia cultivated with $\mathrm{Al}_{2} \mathrm{O}_{3} \mathrm{NPs}$ at $0.1 \mathrm{~mol} \mathrm{~L}^{-1}$ were chosen for electron microscopy analysis. Medium-sized fresh mycelium spheres were fixed with $3 \%$ glutaraldehyde in $0.1 \mathrm{~mol} \mathrm{~L}^{-1}$ cacodylate buffer ( $\mathrm{pH}$ 7.2) for $24 \mathrm{~h}$ at $4{ }^{\circ} \mathrm{C}$. Samples were rinsed five times with $0.1 \mathrm{~mol} \mathrm{~L}^{-1}$ cacodylate buffer, then dehydrated stepwise in an ethanol solution series of 30, 50, 70, 90, 96 and $100 \%, 15$ min per step. Finally, samples were dehydrated twice for $5 \mathrm{~min}$ in acetone. For scanning electron microscopy (SEM), samples were dried and sputter-coated with gold. Before examination in a LEO $912 \mathrm{AB}$ transmission electron microscope (TEM), samples dehydrated in acetone were embedded in epoxy resin, polymerized and hardened at $60{ }^{\circ} \mathrm{C}$. Ultrathin
Fig. 1 TEM images of $\mathrm{Al}_{2} \mathrm{O}_{3}$ NPs in medium before autoclaving (a), longitudinal section of hyphae of Pleurotus eryngii exposed to $\mathrm{Al}_{2} \mathrm{O}_{3}-\mathrm{NPs}$ (b), cross section of hyphae exposed to $\mathrm{Al}_{2} \mathrm{O}_{3}$-NPs (c) and control (d). Scale bar $200 \mathrm{~nm}$ (a) and $1,000 \mathrm{~nm}(\mathbf{b}-\mathbf{d})$
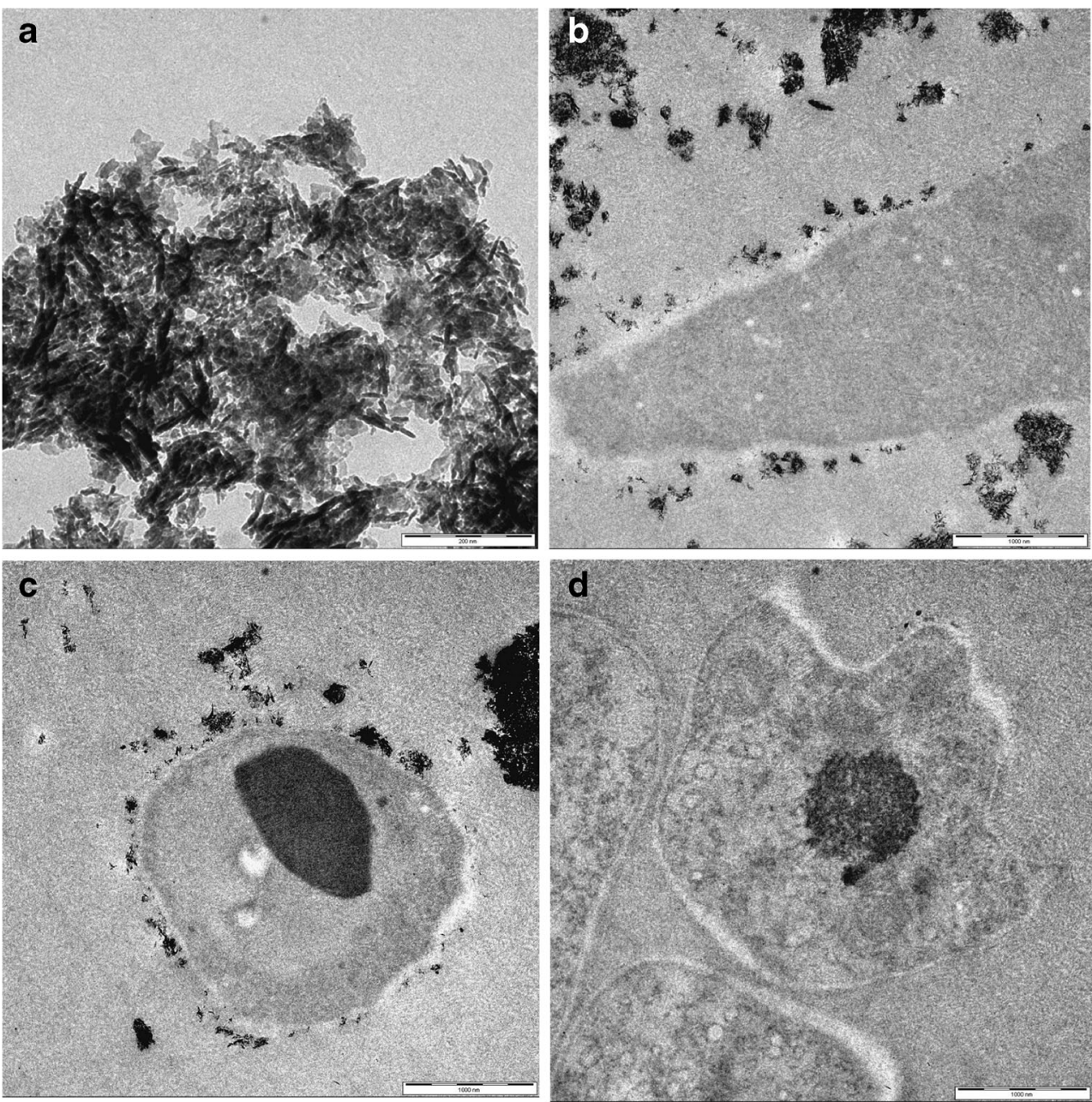
sections $(70 \mathrm{~nm})$ were cut with an MTX ultramicrotome (RMC, Japan), placed on a copper grid and analyzed. Micrographs were taken with the Proscan High Speed Slow Scan CCD-camera.

For microscopic (TEM) characteristic of particles, one drop of a $0.1 \mathrm{~mol} \mathrm{~L}^{-1}$ solution of $\mathrm{Al}_{2} \mathrm{O}_{3}$ NPs was placed on a formvar-coated grid and dried. Different variants of $\mathrm{Al}_{2} \mathrm{O}_{3}$ solution were investigated: solution in water, in PDY medium before autoclaving and in PDY after autoclaving. In each solution, similar aggregates of NPs were observed.

\section{Results and discussion}

Microscopic analysis of alumina-NPs accumulation by $P$. eryngii mycelium

Both investigated species, T. versicolor and P. eryngii, efficiently accumulated $\mathrm{Al}_{2} \mathrm{O}_{3}$ nanoparticles. TEM images present $\mathrm{Al}_{2} \mathrm{O}_{3}$ NPs aggregates in the medium before autoclaving (Fig. 1a) and on a cross section of hyphae with NPs adsorbed on the surface (Fig. 1c) in comparison with control hyphae (Fig. 1d). Longitudinal section of the mycelium (Fig. 1b)
Fig. 2 SEM images of Pleurotus eryngii mycelium: a - control; b - exposed to $\mathrm{Al}_{2} \mathrm{O}_{3} \mathrm{NPs}$
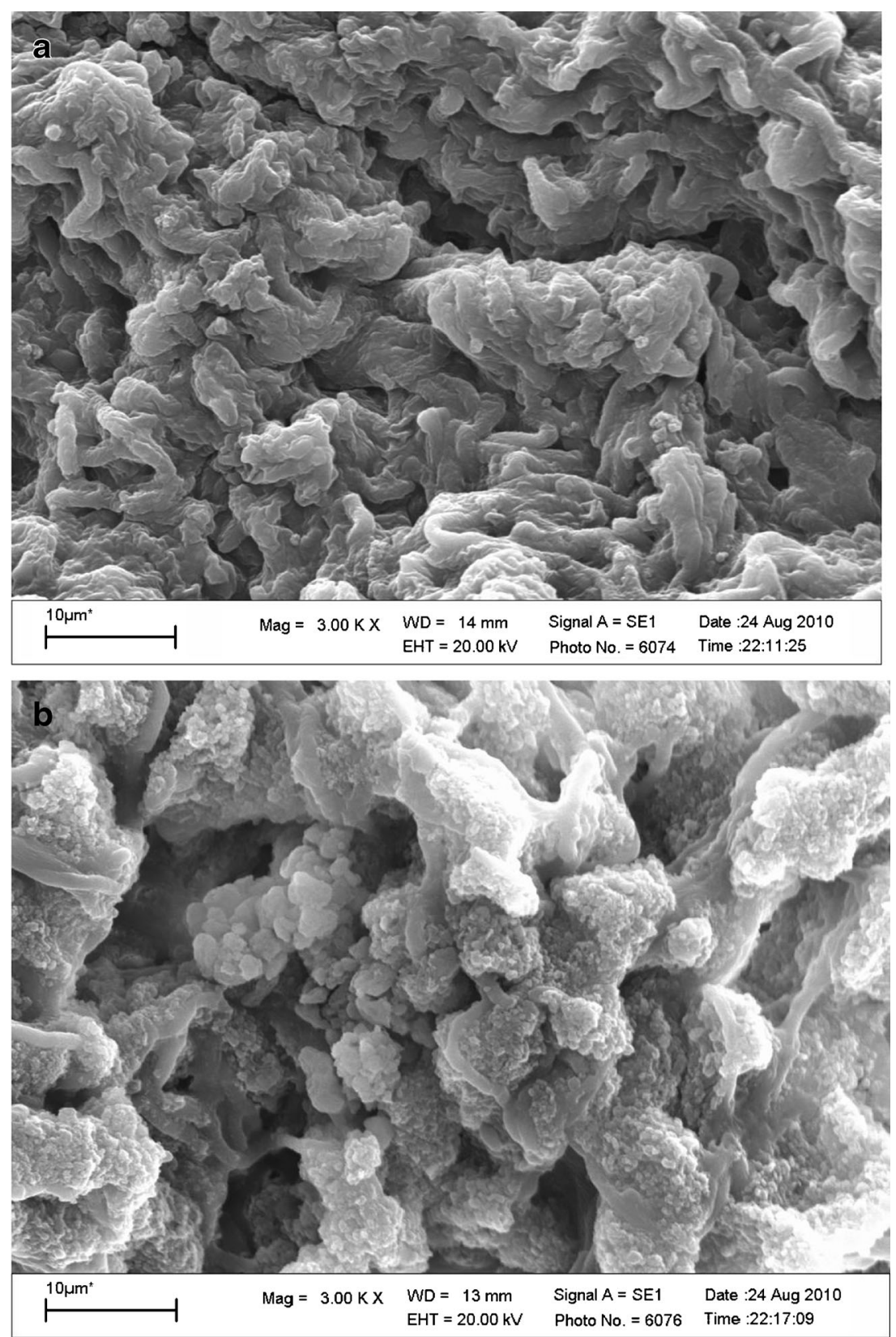
Table 1 Aluminum content in live mycelium of Pleurotus eryngii and Trametes versicolor exposed for 2 or 7 days to $\mathrm{Al}_{2} \mathrm{O}_{3} \mathrm{NPs}_{\mathrm{s}}$ and accumulation efficiencies

\begin{tabular}{|c|c|c|c|c|c|c|c|c|}
\hline \multirow{3}{*}{$\begin{array}{l}\mathrm{Al}_{2} \mathrm{O}_{3} \mathrm{NPs} \\
\text { concentration in } \\
\text { medium }\left[\mathrm{mol} \mathrm{L}^{-1}\right]\end{array}$} & \multicolumn{4}{|c|}{ Pleurotus eryngii } & \multicolumn{4}{|c|}{ Trametes versicolor } \\
\hline & \multicolumn{2}{|l|}{2 days } & \multicolumn{2}{|l|}{7 days } & \multicolumn{2}{|l|}{2 days } & \multicolumn{2}{|l|}{7 days } \\
\hline & $\begin{array}{l}\mathrm{Al} \text { content } \\
{\left[\mathrm{mg} \mathrm{g}^{-1} \text { d.w }\right]}\end{array}$ & $\begin{array}{l}\text { Accumulation } \\
\text { efficiency [\%] }\end{array}$ & $\begin{array}{l}\mathrm{Al} \text { content } \\
{\left[\mathrm{mg} \mathrm{g}^{-1} \text { d.w }\right]}\end{array}$ & $\begin{array}{l}\text { Accumulation } \\
\text { efficiency [\%] }\end{array}$ & $\begin{array}{l}\mathrm{Al} \text { content } \\
{\left[\mathrm{mg} \mathrm{g}^{-1} \text { d.w }\right]}\end{array}$ & $\begin{array}{l}\text { Accumulation } \\
\text { efficiency [\%] }\end{array}$ & $\begin{array}{l}\mathrm{Al} \text { content } \\
{\left[\mathrm{mg} \mathrm{g}^{-1} \text { d.w }\right]}\end{array}$ & $\begin{array}{l}\text { Accumulation } \\
\text { efficiency [\% }\end{array}$ \\
\hline 0.001 & $35 \pm 3$ & $39 \pm 9$ & $16 \pm 0$ & $75 \pm 3$ & $16 \pm 1$ & $17 \pm 2$ & $9 \pm 1$ & $83 \pm 7$ \\
\hline 0.01 & $134 \pm 8$ & $33 \pm 2$ & $121 \pm 11$ & $71 \pm 5$ & $89 \pm 5$ & $11 \pm 2$ & $61 \pm 5$ & $71 \pm 8$ \\
\hline
\end{tabular}

Results are presented as means \pm standard deviations, $n \geq 3$

confirmed the binding of NPs with the surface of cell wall. Scanning electron micrographs (SEM) show alumina NPs aggregates on $P$. eryngii hyphae walls after exposition (Fig. 2b) compared with control (Fig. 2a).

Fig. 3 Macroscopic image Pleurotus eryngii mycelium spheres (a) and LA ICP MS analysis of aluminum content in the cross section of a mycelium sphere (b)
Effect of exposure time on $\mathrm{Al}_{2} \mathrm{O}_{3}$ NPs accumulation

The intensity of NP accumulation depended on the exposure time (Table 1). The concentration of Al bound by the hyphae

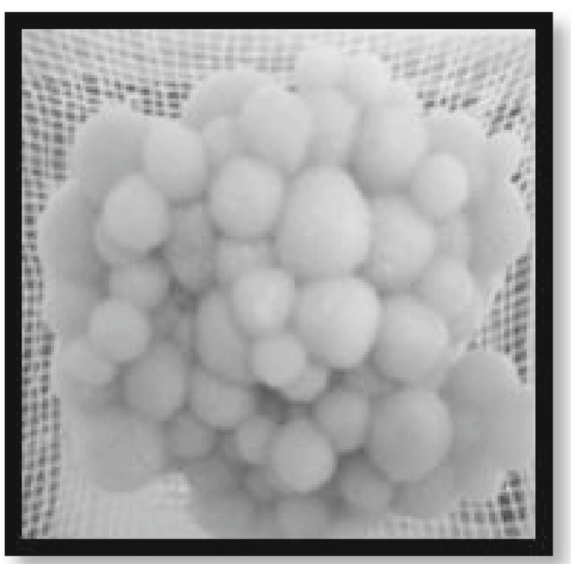

b

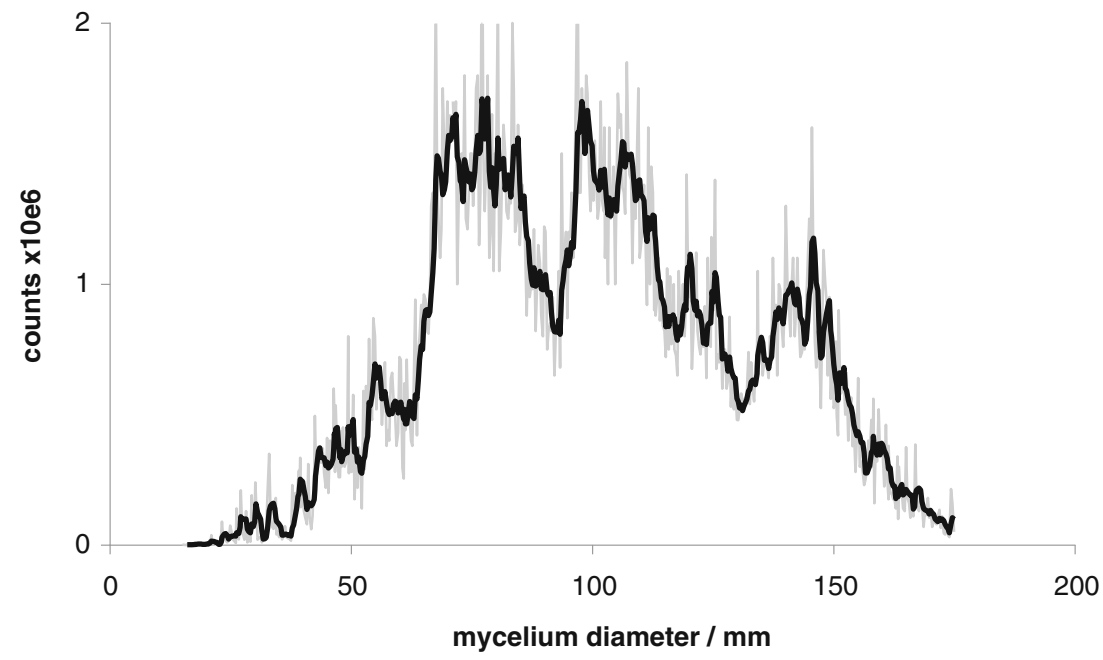




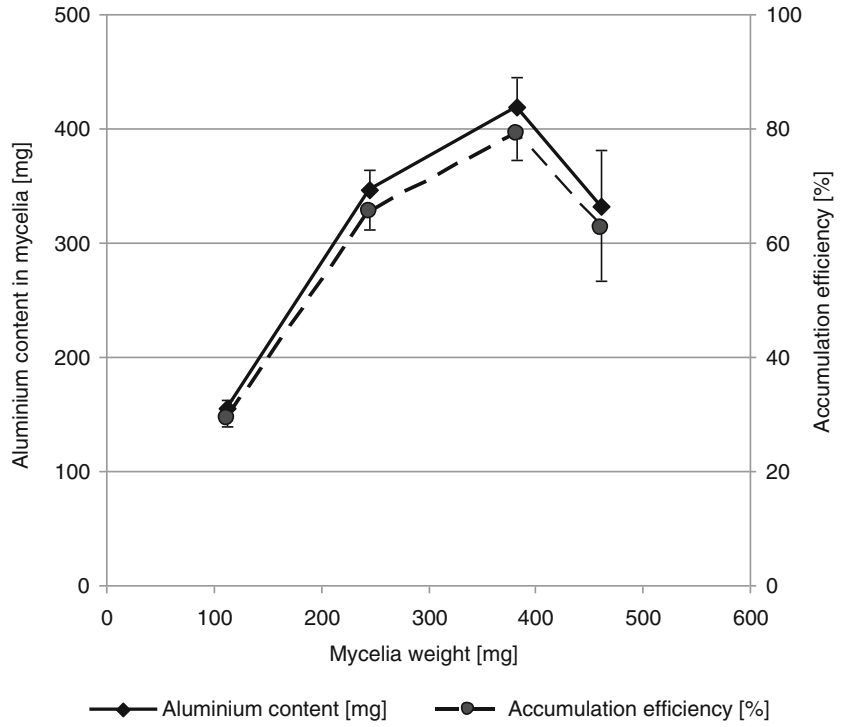

Fig. 4 Content of accumulated $\mathrm{Al}$ in the mycelium after exposure to alumina-nanoparticles and accumulation efficiency as a function of mycelia weight

after 2 days of cultivation was significantly higher than that determined after 7 days, both for P. eryngii and T. versicolor. An opposite tendency was noticed for accumulation efficiency. After 2 days, the efficiency was about $36 \%$ and $14 \%$ for $P$. eryngii and $T$. versicolor; and after 7 days, effeicieny was $73 \%$ and $77 \%$ respectively.

We used LA ICP MS to study the distribution of $\mathrm{Al}_{2} \mathrm{O}_{3} \mathrm{NPs}$ in spherical colony (Fig. 3a, b). The highest concentration of $\mathrm{Al}$ was found in the center of the sphere formed at the beginning of mycelium growth. The $\mathrm{Al}$ content decreased with the increasing distance from the center, i.e., the later stages of growth. These results confirmed previously obtained data (Table 1) that the intensity of NPs accumulation is highest at the beginning of mycelium growth.

Relationship between mycelium mass and $\mathrm{Al}$ accumulation

The relationship between mycelium mass and $\mathrm{Al}$ accumulation was investigated for $P$. eryngii grown in the medium supplemented with $0.001 \mathrm{~mol} \mathrm{~L}^{-1} \quad \mathrm{Al}_{2} \mathrm{O}_{3}$-NPs (Fig. 4). It was found that the $\mathrm{Al}$ content in mycelia increased with the dry mycelia weight. The same tendency was observed for $\mathrm{Al}$ accumulation efficiency.

Effect of $\mathrm{Al}_{2} \mathrm{O}_{3}$-NPs concentration on $\mathrm{Al}$ accumulation by $P$. eryngii and $T$. versicolor

The investigations of the effect of alumina nanoparticles concentration on their accumulation by live P.eryngii and $T$. versicolor mycelia showed a good correlation between the NPs concentration $\left(0.001-0.1 \mathrm{~mol} \mathrm{~L}^{-1}\right.$, exposition time 7 days) and the $\mathrm{Al}$ content of the mycelium (Table 2). It was found that $\mathrm{Al}$ content in mycelia increased with the NP concentration, while accumulation efficiencies were at the same level. Differences were observed between the two mushroom species. P. eryngii showed a higher Al accumulation efficiency (79-92\%) in comparison with $T$. versicolor (60-64\%). The obtained efficiencies of $\mathrm{Al}_{2} \mathrm{O}_{3}$ NPs accumulation were similar to those of Simonescu and Ferdes 2012, who evaluated fungal strains (Aspergillus oryzae, Aspergillus niger, Fusarium oxysporum, Polyporus squamosus) for their ability to remove copper (in the form of $\mathrm{CuS}$ nanoparticles) from aqueous systems. They found that

Table 2 Aluminum content in mycelium of Pleurotus eryngii (live or dead) and Trametes versicolor (live) exposed to varying concentrations of $\mathrm{Al}_{2} \mathrm{O}_{3}$ NPs and accumulation efficiencies

\begin{tabular}{|c|c|c|c|c|c|c|}
\hline \multirow{3}{*}{$\begin{array}{l}\mathrm{Al}_{2} \mathrm{O}_{3} \mathrm{NPs} \text { concentration } \\
\text { in medium }\left[\mathrm{mol} \mathrm{L}^{-1}\right]\end{array}$} & \multicolumn{4}{|c|}{ Pleurotus eryngii } & \multirow{2}{*}{\multicolumn{2}{|c|}{$\begin{array}{l}\text { Trametes versicolor } \\
\text { Live }\end{array}$}} \\
\hline & \multicolumn{2}{|l|}{ Live } & \multicolumn{2}{|l|}{ Dead } & & \\
\hline & $\begin{array}{l}\text { Al content } \\
{\left[\mathrm{mg} \mathrm{g}^{-1} \text { d.w. }\right]}\end{array}$ & $\begin{array}{l}\text { Accumulation } \\
\text { efficiency [\%] }\end{array}$ & $\begin{array}{l}\mathrm{A} 1 \text { content } \\
{\left[\mathrm{mg} \mathrm{g}^{-1} \text { d.w. }\right]}\end{array}$ & $\begin{array}{l}\text { Accumulation } \\
\text { efficiency [\%] }\end{array}$ & $\begin{array}{l}\text { Al content } \\
{\left[\mathrm{mg} \mathrm{g}^{-1} \text { d.w. }\right]}\end{array}$ & $\begin{array}{l}\text { Accumulation } \\
\text { efficiency [\%] }\end{array}$ \\
\hline 0 & 0 & - & - & - & 0 & - \\
\hline 0.001 & $15 \pm 4$ & $84 \pm 16$ & - & - & $10 \pm 1$ & $64 \pm 1$ \\
\hline 0.01 & $89 \pm 14$ & $92 \pm 7$ & - & - & $73 \pm 4$ & $61 \pm 6$ \\
\hline 0.05 & $243 \pm 50$ & $90 \pm 8$ & $235 \pm 13$ & $57 \pm 49$ & $261 \pm 12$ & $60 \pm 4$ \\
\hline 0.1 & $266 \pm 39$ & $79 \pm 11$ & $307 \pm 8$ & $45 \pm 27$ & $350 \pm 10$ & $61 \pm 5$ \\
\hline
\end{tabular}

Results are presented as means \pm standard deviations, $n \geq 3$ 


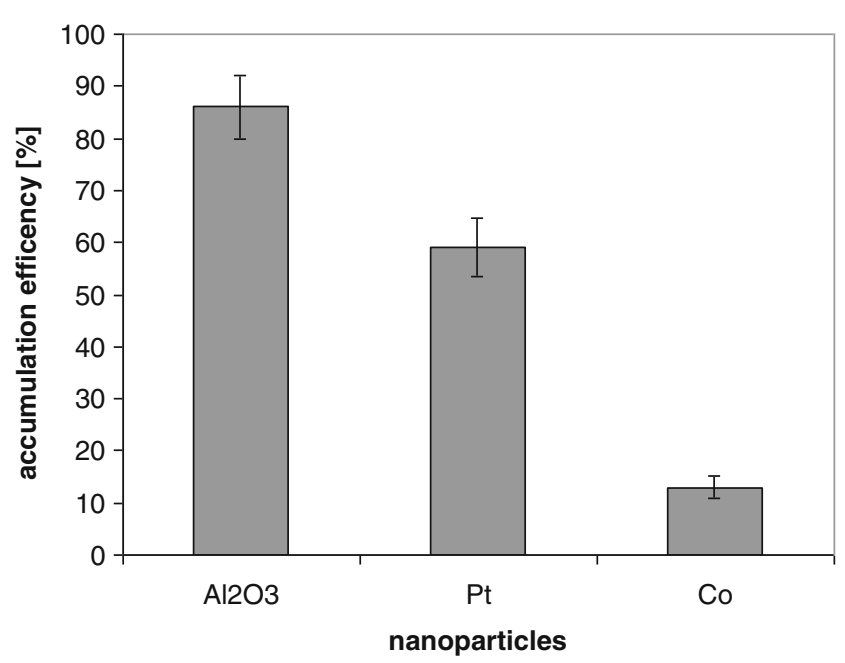

Fig. 5 Accumulation efficiency for different NPs

strains of Aspergillus oryzae are capable of removing up to $88 \%$ of copper.

Accumulation of $\mathrm{Al}_{2} \mathrm{O}_{3}$ NPs by live and dead $P$. eryngii mycelium

The accumulation efficiency of Al by dead mycelium of $P$. eryngii was within the range of $45-57 \%$, so somewhat lower than by the live one (on average $85 \%$ ). This indicates a more effective interaction of NPs with live mycelia compared to biologically nonactive hyphae. An ability of dead fungal biomass to adsorb zinc was shown by Faryal et al. (2006). Alkaliextracted $A$. niger mycelium biomass (biosorbant) was effective in sequestration of metal ions, especially $\mathrm{Zn}$ and $\mathrm{Cd}$, present at very low concentrations in lake waters (Akhtar and Mohan 1995). The lack of an effect of the NPs concentration on their accumulation efficiency seems to be due to a dynamic equilibrium between the NPs dispersed in medium and those adsorbed by the mycelium. Accumulation of particles by the mycelium can involve two modes - surface binding of NPs to the cell wall and uptake into the cell across the cell membrane (Bishnoi and Garima 2005). The first mode takes place in the case of both live and dead cells, while the second, which is energy-dependent, occurs only in live cells. As shown by our results, biosorption is undoubtedly the dominant mechanism of alumina NP accumulation by $P$. eryngii.

Ability of $P$. eryngii mycelia to mycoextract different nanoparticles

The ability of $P$. eryngii mycelia to sequester Pt and Co NPs was investigated. The mycoextraction efficiency depended on the NP type (Fig. 5), and was the highest for $\mathrm{Al}_{2} \mathrm{O}_{3} \mathrm{NPs}$ (86\%), lower for Pt (58\%) and the lowest for Co (13\%).

\section{Summary}

Our results have shown that the efficiency of NP accumulation depends on the duration of exposure, biomass of the mycelium, NP type and species of fungi. It was higher for live mycelia in comparison with dead ones. The accumulation efficiency was not related to NP concentration.

Fungi are a promising alternative for bioremediation of heavy metal-contaminated aqueous environments and, according to the above results, can also be successfully applied for mycoextraction of nanoparticles. The obtained results document an excellent ability of biotechnological cultures of mycelium of $P$. eryngii and $T$. versicolor to efficiently remove alumina NPs from a contaminated environment which may prevent their toxicity. Additionally, the NP-loaded biomass can be separated and the biosorbed particles can potentially be reclaimed. Recovery of biosorbed particles should be investigated in future studies. Results will answer for the question of nanoparticles stability. Another possibility is that the biomass of the fungus can be used as an alumina-loaded biosorbant for absorption of the other pollutants. This should be a subject of further studies. To the best of our knowledge, this is the first paper on the use of fungi in bioremediation of metallic nanoparticle wastes, presenting a novel convenient cultivation method addressing the yield and mechanisms of $\mathrm{Al}_{2} \mathrm{O}_{3}$ NPs sequestration. These data can be built upon when optimizing conditions for large scale bioremediation or when dealing with other nanoparticle contaminants.

Acknowledgments This work was supported by the Ministry of Science and Higher Education, Poland; Grant No. N304 077535.

Open Access This article is distributed under the terms of the Creative Commons Attribution License which permits any use, distribution, and reproduction in any medium, provided the original author(s) and the source are credited.

\section{References}

Aitken RJ, Creely KS, Tran CL (2004) Nanoparticles: an occupational hygiene review. Health and Safety Executive, Suffolk

Akhtar N, Mohan PM (1995) Bioremediation of toxic metal ion from polluted lake water and industrial effluents by fungal biosorbent. Curr Sci 69:1028-1030

Bakircioglu Y, Bakircioglu D, Akman S (2010) Biosorption of lead by filamentous funal biomass-loaded $\mathrm{TiO}_{2}$ nanoparticles. J Hazard Mater 178(1-3):1015-1020 
Bazała MA, Bystrzejewska-Piotrowska G, Cipakova A (2005) Bioaccumulation of ${ }^{137} \mathrm{Cs}$ in wild mushrooms collected in Poland and Slovacia. Nukleonika 50:S15-S18

Bazała MA, Gołda K, Bystrzejewska-Piotrowska G (2008) Transport of radiocesium in mycelium and its translocation to fruitbodies of a saprophytic macromycete. J Environ Radioact 7:1200-1202

Bishnoi NR, Garima (2005) Fungus-an alternative for bioremediation of heavy metal containing wastewater: an review. J Sci Ind Res 64:93-100

Borovicka J, Kotrba P, Gryndler M, Mihaljevic M, Randa Z, Rohovec J, Cajthaml T, Stijve T, Dunn CE (2010) Sci Total Environ 408:27332744

Bystrzejewska-Piotrowska G, Bazała MA (2008) A study of mechanisms responsinble for incorporation of cesium and radiocesium into fruit bodies of king oster mushroom (Pleurotus eryngii). J Environ Radioact 99(7):1185-1191

Bystrzejewska-Piotrowska G, Pianka D, Bazala MA, Steborowski R, Manjon JL, Urban PL (2008) Pilot study of bioaccumulation and distribution of cesium, potassium, sodium and calcium in king oyster mushroom (Pleurotus eryngii) grown under controlled conditions. J Phytorem 10(6):503-514

Bystrzejewska-Piotrowska G, Golimowski J, Urban L (2009) Nanoparticles: their potential toxicity, waste and environmental management. Waste Manag 29(9):2587-2595

Chen L, Yokel RA, Henning B, Toborek M (2008) Manufactured aluminium oxide nanoparticles decrease expression of tight junction proteins in brain vasculature. J Neuroimmune Pharmacol 3(4):286295

Chojnacka K (2010) Biosorption and bioaccumulation - the prospects for practical applications. Environ Int 36(3):299-307

Christian V, Shirivastava R, Shukla D, Modi HA, Vyas BR (2005) Degradation of xenobiotic compounds by lignin-degrading whiterot fungi: enzymology and mechanisms involved. Indian J Exp Biol 4:301-312

Faryal R, Lodhi A, Hameed A (2006) Isolation, characterization and biosorption of zinc by indigenous fungal strains Aspergillus fumigatus RH05 and Aspergillus flavus RH07. Pak J Bot 38(4): 817-832

Fomina M, Charnock JM, Hillier S, Alvarez R, Gaad GM (2007) Fungal transformation of uranium oxides. Environ Microbiol 9(7):16961710

Fomina M, Charnock JM, Hillier S, Alvarez R, Livens F, Gaad GM (2008) Role of fungi in the biochemical fate of depleted uranium. Curr Biol 18(9):R375-R377

Gadd GM (2010) Metals, minerals and microbes: geomicrobiology and bioremediation. Microbiology 156:609-643
Huang KL, Yin L, Liu S, Li C (2007) Preparation and formation mechanism of $\mathrm{Al}_{2} \mathrm{O}_{3}$ nanoparticles by reverse microemulsion. Trans Nonferrous Metals Soc China 17:633-637

Manjon JL, Urban PL, Bystrzejewska-Piotrowska G (2004) A simple and quick model to study uptake and transfer of radionuclides and heavy metals from mycelium of the fruitbody of saprophytic edible fungi. Nukleonika 49:S21-S24

Oberdorster G, Oberdorster E, Obersdorster J (2005) Nanotoxicology: an emerging discipline evolving from studies of ultrafine particles. Environ Health Perspect 113(7):823-839

Pakrashi S, Dalai S, Ritika SB, Chandrasekaran N, Mukherjee A (2012) A temporal study on fate of $\mathrm{Al}_{2} \mathrm{O}_{3}$ nanoparticles in a fresh water microcosm at environmentally relevant low concentrations. Ecotoxicol Environ Saf 84:70-77

Park E-J, Kim H, Kim Y, Choi K (2010) Repeated-dose toxicity attributed to aluminium nanoparticles following 28-day oral administration, particulary on gene expression in mouse brain. Toxicol Environ Chem 93(1):120-133

Podila R, Brown JM (2013) Toxicity of engineered nanomaterials: a physicochemical perspective. J Biochem Mol Toxicol 27(1):50-55

Pointing SB (2001) Feasibility of bioremediation by wfite-rot fungi. Appl Microbiol Biotechnol 57(1-2):20-33

Rai A, Park K, Zhou L, Zachariah MR (2006) Understending the mechanism of aluminium nanoparticle oxidation. Combust Theory Model 10(5):843-859

Rittner MN (2002) Marked analysis of nanostructured materials. Am Ceram Soc Bull 81:33-36

Sadiq MI, Pakrashi S, Chandrasekaran N, Mukherjee A (2011) Studies on toxicity of aluminum oxide $\left(\mathrm{Al}_{2} \mathrm{O}_{3}\right)$ nanoparticles to microalgae species: Scenedesmus sp. and Chlorella sp. J Nanoparticle Res 13: 3287-3299

Schmid K, Riediker M (2008) Use of nanoparticles in Swiss industry: a targeted survey. Environ Sci Technol 42(7):2253-2260

Simonescu CM, Ferdes M (2012) Fungal biomass for $\mathrm{Cu}$ (II) uptake from aqueous systems. Pol J Environ Stud 21(6):1831-1839

Stenger F, Mende S, Schwedes J, Peukert W (2005) The influence of suspension properties on the grinding behavior of alumina particles in the submicron size range in stirred media mills. Powder Technol 156: $103-110$

Velásquez L, Dussan J (2009) Biosorption and bioaccumulation of heavy metals on dead and living biomass of Bacillus sphaericus. J Hazard Mater 167(1-3):713-716

Yang S-T, Wang T, Dong E, Chen X-X, Xiang K, Liu J-H, Wang H (2012) Bioavailability and preliminary toxicity evaluations of alumina nanoparticles in vivo after oral exposure. Toxicol Res 1:69-74 